\title{
Adiposity and Health Status among Adult Male Mundas and Oraons of Paschim Medinipur, West Bengal, India
}

\author{
Subal Das, ${ }^{1}$ Bigitendriya Debsharma, ${ }^{2}$ and Kaushik Bose ${ }^{3}$ \\ ${ }^{1}$ Department of Anthropology and Tribal Development, Guru Ghasidas Vishwavidyalaya, Bilaspur, Chhattisgarh, India \\ ${ }^{2}$ Research Investigator, CRI, Bacward Classes Welfare Department, Govt. of India, Kolkata, West Bengal, India \\ ${ }^{3}$ Department of Anthropology, Vidyasagar University, Midnapore, West Bengal 721102, India
}

Correspondence should be addressed to Kaushik Bose; banda@vsnl.net

Received 22 November 2012; Revised 14 March 2013; Accepted 18 April 2013

Academic Editor: Tetsuo Katsuura

Copyright (C) 2013 Subal Das et al. This is an open access article distributed under the Creative Commons Attribution License, which permits unrestricted use, distribution, and reproduction in any medium, provided the original work is properly cited.

\begin{abstract}
The present cross-sectional study was conducted among two male tribal groups Munda $(n=106)$ and Oraon $(n=104)$ aged 18-73 years of Paschim Medinipur, West Bengal. Objective was to evaluate the health status based on body mass index (BMI) and percent body fat (PBF). Measurements of weight, height, circumferences, and skinfolds were recorded. Results revealed that mean age of Mundas $(36.2 \pm 13.3)$ and Oraons $(35.1 \pm 15.3)$ in years were similar. Significant $(P<0.05)$ ethnic differences in mean chest circumference and anterior thigh skinfold were observed. Both Munda (50.0\%) and Oraon (46.2\%) males suffered from very high degree of chronic energy deficiency (CED) based on BMI. Similarly, for percent body fat (PBF), Mundas (29.3\%) and Oraons (35.4\%) had unhealthy (too low) PBF (i.e., $\leq 5 \%$ ) levels. Significantly negative correlations were observed between age and BMI and positive correlations between age, waist-hip ratio (WHR), and conicity index (CI) (only Mundas) among Mundas and Oraons. In Linear regression, age had a significant impact on all derived central and overall adiposity measures. Prospective studies are required to determine the associations between health status and PBF as well as nutrition status and BMI in different indigenous ethnic groups of India and elsewhere.
\end{abstract}

\section{Introduction}

The poor nutritional condition of young children in India has received much attention recently, but Indian adults are also experiencing a variety of nutritional problems [1]. The developing world faces the growing problem of obesity. About one-third of the world's population today is overweight, and almost one in ten is obese [2]. Fat is one of the basic components that make up the structure of our body. The other components include muscle, water, bone, and your organsthe brain, liver, kidneys, spleen, stomach, pancreas, intestines, and so forth. All are necessary for normal, healthy functioning. Body fat can be divided into two categories: essential fat and storage fat. In men, essential fat is approximately $3 \%$ of body weight. Men and women have similar amounts of storage fat [3].

BMI measures both lean body mass and body fat. The correlation between body fatness and BMI ranges from 0.6 to 0.8 , depending on the methods for determining body fat and populations. The relation between BMI and percentage of body fat also differs between men and women, across age groups, and in some studies across racial groups [4-6]. BMI, because of its simplicity and hence general applicability, is a widely used substitute measure of obesity. While BMI and percentage of body fat (BF) are generally well correlated, there is increasing evidence of wide ethnic variation in the relationship between these two variables [7]. The WHO has recognized the deficiencies of a universal cut-off for obesity [8], and a WHO [9] report suggested that further body composition studies of Asian and Pacific Island populations are needed to determine equivalent fatness levels and the relationship of BMI with body size. Ethnicity-specific recommendations for BMI-based thresholds for obesity may have significant implications for public health policies in many countries.

Inadequate nutrition in adolescents and young adults can put them at a high risk of chronic diseases, particularly if 
TABLE 1: Descriptive statistics with $t$-test of the anthropometric variables.

\begin{tabular}{|c|c|c|c|c|c|c|}
\hline Variables & Ethnicity & $N$ & Mean & Std. deviation & $t$ & Sig. \\
\hline \multirow{2}{*}{ Weight $(\mathrm{kg})$} & Munda & 106 & 50.50 & 6.83 & \multirow{2}{*}{1.464} & \multirow{2}{*}{0.825} \\
\hline & Oraon & 104 & 49.10 & 7.00 & & \\
\hline \multirow{2}{*}{ Height $(\mathrm{cm})$} & Munda & 106 & 159.91 & 6.40 & \multirow{2}{*}{0.058} & \multirow{2}{*}{0.823} \\
\hline & Oraon & 104 & 159.85 & 8.15 & & \\
\hline \multirow{2}{*}{ Mid-upper arm circumference $(\mathrm{cm})$} & Munda & 106 & 23.39 & 1.97 & \multirow{2}{*}{0.411} & \multirow{2}{*}{0.424} \\
\hline & Oraon & 104 & 23.27 & 2.23 & & \\
\hline \multirow{2}{*}{ Chest circumference $(\mathrm{cm})$} & Munda & 106 & 79.32 & 3.86 & \multirow{2}{*}{1.428} & \multirow{2}{*}{0.004} \\
\hline & Oraon & 104 & 78.42 & 5.21 & & \\
\hline \multirow{2}{*}{ Waist circumference $(\mathrm{cm})$} & Munda & 106 & 72.35 & 5.62 & \multirow{2}{*}{1.705} & \multirow{2}{*}{0.067} \\
\hline & Oraon & 104 & 70.89 & 6.76 & & \\
\hline \multirow{2}{*}{ Hip circumference $(\mathrm{cm})$} & Munda & 106 & 79.74 & 5.13 & \multirow{2}{*}{0.950} & \multirow{2}{*}{0.869} \\
\hline & Oraon & 104 & 79.08 & 4.95 & & \\
\hline \multirow{2}{*}{ Biceps skinfold (mm) } & Munda & 106 & 2.33 & 0.83 & \multirow{2}{*}{-0.311} & \multirow{2}{*}{0.725} \\
\hline & Oraon & 104 & 2.37 & 0.86 & & \\
\hline \multirow{2}{*}{ Triceps skinfold (mm) } & Munda & 106 & 3.94 & 1.44 & \multirow{2}{*}{-0.485} & \multirow{2}{*}{0.559} \\
\hline & Oraon & 104 & 4.04 & 1.55 & & \\
\hline \multirow{2}{*}{ Subscapular skinfold (mm) } & Munda & 106 & 7.37 & 2.19 & \multirow{2}{*}{-0.659} & \multirow{2}{*}{0.709} \\
\hline & Oraon & 104 & 7.57 & 2.21 & & \\
\hline \multirow{2}{*}{ Suprailiac skinfold (mm) } & Munda & 106 & 5.06 & 1.90 & \multirow{2}{*}{-1.019} & \multirow{2}{*}{0.060} \\
\hline & Oraon & 104 & 5.35 & 2.23 & & \\
\hline \multirow{2}{*}{ Anterior thigh skinfold (mm) } & Munda & 106 & 6.40 & 2.09 & \multirow{2}{*}{0.461} & \multirow{2}{*}{0.047} \\
\hline & Oraon & 104 & 6.24 & 2.90 & & \\
\hline Medial calf skinfold (mm) & Munda & 106 & 4.95 & 2.20 & -0.486 & 0.512 \\
\hline & Oraon & 104 & 5.10 & 2.22 & & \\
\hline
\end{tabular}

combined with other adverse lifestyle behavior [10]. Malnutrition received recognition of planners and policy makers right from the beginning of five-year planning. Although a large number of national nutritional programmes have been executed to battle the threat of malnutrition, it still persists.

In view of the above background, the present study provides a comprehensive comparative analysis of the body composition of Munda and Oraon tribal male adults centering on the prevalence of health and nutritional status of both these communities using BMI $\left(\mathrm{k} / \mathrm{m}^{2}\right)$ and PBF (\%).

\section{Materials and Methods}

The present study was a community based cross-sectional comparative study carried out during the month of June to August, 2008 (period of data collection). All available males during data collection in two villages Muradanga and Taldanga were included in the study. A total of 210 males (106 Mundas and 104 Oraons) aged 18-73 years were anthropometrically measured. Data were collected after obtaining necessary approval from the university ethical committee and villagers. Villagers were informed about the objectives of present study prior to taking measurement. Data on age and anthropometry were collected on a pretested questionnaire by house-to-house visit. The total population of West Bengal at 2001 Census has been 80,176,197 of which 4,406,794 persons are Scheduled Tribes (STs) constituting 5.5 percent of the total population of the state. Out of the total tribal population of West Bengal, Oraon (14.0\%) and Munda (7.8\%) comprised second and third highest tribal population after Santal of West Bengal, India [13]. All the measurements were taken by one of the author (BD) following standard techniques [12]. Technical errors of measurement were found to be within reference values and thus not incorporated in statistical analyses [14].

Oraons speak a Dravidian language known as Kurukh. Oraons are closely related to the neighboring Munda tribe, and the headman of an Oraon village is called munda. Although there are no subcastes among the Oraons, the Kudas ("navvies") and Kisans ("cultivators"), having their distinct occupations, tend to marry among themselves [11].

Mundas are also known as Horo-hon or Mura, which means headman of a village. They believe that they are the descendants of Sing Bonga, the supreme God. They are one of the well studied tribal communities, and probably the only one with an encyclopedia of their own, the Encyclopedia Mundarica. This Munda, an ancient people, also lent its name to the language, called Austro-Asiatic Mundari, or Kolarian, which is one of the four language families of India. The Mundas live in the states of Bihar, West Bengal, Assam, Tripura, Madhya Pradesh, and Orissa [15].

As far as the occupation of these Munda tribes is concerned, in earlier times the Munda tribes were wandering huntsmen and collectors. Very recently, these Munda tribes too took up the profession of shifting cultivation, thereby 
TABLE 2: Descriptive statistics with $t$-test of overall and central adiposity variables.

\begin{tabular}{|c|c|c|c|c|c|c|}
\hline Variables & Ethnicity & $N$ & Mean & Std. deviation & $t$ & Sig. \\
\hline \multicolumn{7}{|c|}{ Measures of overall adiposity } \\
\hline \multirow{2}{*}{ BMI $\left(\mathrm{kg} / \mathrm{m}^{2}\right)$} & Munda & 106 & 18.46 & 2.41 & \multirow{2}{*}{-0.456} & \multirow{2}{*}{0.649} \\
\hline & Oraon & 104 & 18.62 & 2.75 & & \\
\hline \multirow{2}{*}{$\mathrm{FM}(\mathrm{kg})$} & Munda & 106 & 3.71 & 2.21 & \multirow{2}{*}{-0.417} & \multirow{2}{*}{0.392} \\
\hline & Oraon & 104 & 3.84 & 2.40 & & \\
\hline \multirow{2}{*}{ FMI $\left(\mathrm{kg} / \mathrm{m}^{2}\right)$} & Munda & 106 & 1.44 & 0.83 & \multirow{2}{*}{-0.518} & \multirow{2}{*}{0.188} \\
\hline & Oraon & 104 & 1.51 & 0.92 & & \\
\hline \multirow{2}{*}{$\mathrm{PBF}(\%)$} & Munda & 106 & 7.08 & 3.57 & \multirow{2}{*}{-0.789} & \multirow{2}{*}{0.486} \\
\hline & Oraon & 104 & 7.48 & 3.75 & & \\
\hline \multirow{2}{*}{ BAI } & Munda & 106 & 21.49 & 2.71 & \multirow{2}{*}{0.371} & \multirow{2}{*}{0.303} \\
\hline & Oraon & 104 & 21.31 & 4.20 & & \\
\hline \multicolumn{7}{|c|}{ Measures of central adiposity } \\
\hline \multirow{2}{*}{$\mathrm{CI}$} & Munda & 106 & 1.18 & 0.07 & \multirow{2}{*}{0.785} & \multirow{2}{*}{0.062} \\
\hline & Oraon & 104 & 1.18 & 0.09 & & \\
\hline \multirow{2}{*}{$\mathrm{WC}(\mathrm{cm})$} & Munda & 106 & 72.35 & 5.62 & \multirow{2}{*}{1.705} & \multirow{2}{*}{0.067} \\
\hline & Oraon & 104 & 70.89 & 6.76 & & \\
\hline \multirow{2}{*}{ WHR } & Munda & 106 & 0.91 & 0.05 & \multirow{2}{*}{1.698} & \multirow{2}{*}{0.324} \\
\hline & Oraon & 104 & 0.90 & 0.05 & & \\
\hline \multirow{2}{*}{ WHTR } & Munda & 106 & 0.45 & 0.04 & \multirow{2}{*}{1.472} & \multirow{2}{*}{0.142} \\
\hline & Oraon & 104 & 0.44 & 0.05 & & \\
\hline
\end{tabular}

TABLE 3: Prevalence of health and nutritional status based on PBF (\%) [11] and BMI $\left(\mathrm{kg} / \mathrm{m}^{2}\right)$ [12] among the subjects.

\begin{tabular}{lcccc}
\hline Variable & Cut of point & Classification & Munda & Oraon \\
\hline & $<18.5$ & Undernutrition & 50.0 & 46.2 \\
BMI $\left(\mathrm{kg} / \mathrm{m}^{2}\right)^{*}$ & $18.5-24.9$ & Normal & 48.1 & 1.9 \\
& $\geq 25.0$ & Overweight & 29.3 & 2.9 \\
\hline & $\leq 5 \%$ & Unhealthy (too low) & 68.5 & 35.4 \\
PBF $(\%)^{\#}$ & $6-15 \%$ & Acceptable (lower end) & 61.0 \\
& $16-24 \%$ & Acceptable (upper end) & -2.7 \\
& $\geq 25 \%$ & Unhealthy (too high) & - \\
\hline
\end{tabular}

${ }^{*}$ Chi-square $=0.467, \mathrm{df}=2$, and $\mathrm{sig}=0.792$.

${ }^{\#}$ Chi-square $=1.196, \mathrm{df}=2$, and $\mathrm{sig}=0.550$.

following the practice of most of the tribes of Indian subcontinent. They built up the Parha system of Government, which is fundamentally a "confederacy of village governments." The village markets play very vital role in their economic lives where they exchange their products required for their basic sustenance. Both studied communities are now engaged in industrial labour (in spinning mills, rice mills), rickshaw pullers, and brick factory workers as most of them do not have enough land to cultivate.

There were various direct and indirect methods for assessing body composition and health status of adults. Anthropometry provides portability in large scale community study. Body mass index (BMI) and percent body fat $(\mathrm{PBF})$ provide the overall adiposity of an individual and has been calculated by the following formula:

$$
\mathrm{BMI}=\frac{\text { Weight }(\mathrm{kg})}{\text { Height }^{2}\left(\mathrm{~m}^{2}\right)},
$$

see $[16]$.
The individuals were categorized for their BMI status as per WHO [16] standard. We followed the World Health Organization's classification [16] of the public health problem of low BMI, based on adult populations worldwide.

Consider the following:

$$
\mathrm{PBF}=\left(\frac{4.95}{\text { density }}-4.50\right) \times 100 \text {, }
$$

see [17].

Percent body fat in the adult male tribals has been categorized with reference to the body fat ranges for persons 18 years of age and older [18].

Density was derived following the standard equation [19]:

$$
D=1.1631-0.0632(\log X) \text {, }
$$

where $D=$ estimated body density; $X=$ the sum of the biceps, triceps, subscapular, and suprailiac skinfolds. 
TABLE 4: Correlation matrix showing association between age with overall adiposity and central adiposity measures.

\begin{tabular}{|c|c|c|c|c|c|c|c|c|c|c|c|}
\hline Community & Variables & AGEY & WSTCIR & BMI & WHR & WHTR & CI & $\mathrm{PBF}$ & FM & FMI & BAI \\
\hline \multirow{10}{*}{ Munda } & AGEY & 1.000 & 0.062 & $-0.202^{*}$ & $0.265^{* *}$ & 0.137 & $0.265^{* *}$ & -0.046 & -0.065 & -0.051 & -0.024 \\
\hline & WSTCIR & & 1.000 & $0.580^{* *}$ & $0.566^{* *}$ & $0.875^{* *}$ & $0.654^{* *}$ & $0.545^{* *}$ & $0.596^{* *}$ & $0.583^{* *}$ & $0.462^{* *}$ \\
\hline & BMI & & & 1.000 & 0.003 & $0.306^{* *}$ & $-0.193^{*}$ & $0.542^{* *}$ & $0.675^{* *}$ & $0.621^{* *}$ & 0.188 \\
\hline & WHR & & & & 1.000 & $0.596^{* *}$ & $0.652^{* *}$ & 0.076 & 0.054 & 0.078 & -0.082 \\
\hline & WHTR & & & & & 1.000 & $0.638^{* *}$ & $0.497^{* *}$ & $0.494^{* *}$ & $0.545^{* *}$ & $0.718^{* *}$ \\
\hline & CI & & & & & & 1.000 & 0.103 & 0.066 & 0.066 & 0.189 \\
\hline & $\mathrm{PBF}$ & & & & & & & 1.000 & $0.973^{* *}$ & $0.981^{* *}$ & $0.464^{* *}$ \\
\hline & FM & & & & & & & & 1.000 & $0.989^{* *}$ & $0.448^{* *}$ \\
\hline & FMI & & & & & & & & & 1.000 & $0.523^{* *}$ \\
\hline & BAI & & & & & & & & & & 1 \\
\hline \multirow{10}{*}{ Oraon } & AGEY & 1 & -0.041 & $-0.348^{* *}$ & $0.225^{*}$ & 0.007 & $0.256^{* *}$ & -0.100 & -0.143 & -0.136 & -0.115 \\
\hline & WSTCIR & & 1 & $0.668^{* *}$ & $0.760^{* *}$ & $0.803^{* *}$ & $0.737^{* *}$ & $0.613^{* *}$ & $0.644^{* *}$ & $0.604^{* *}$ & $0.297^{* *}$ \\
\hline & BMI & & & 1 & 0.185 & $0.419^{* *}$ & 0.056 & $0.645^{* *}$ & $0.774^{* *}$ & $0.707^{* *}$ & $0.215^{*}$ \\
\hline & WHR & & & & 1 & $0.715^{* *}$ & $0.802^{* *}$ & $0.276^{* *}$ & $0.240^{*}$ & $0.250^{*}$ & 0.151 \\
\hline & WHTR & & & & & 1 & $0.499^{* *}$ & $0.525^{* *}$ & $0.508^{* *}$ & $0.620^{* *}$ & $0.762^{* *}$ \\
\hline & CI & & & & & & 1 & $0.220^{*}$ & 0.173 & 0.100 & -0.089 \\
\hline & PBF & & & & & & & 1 & $0.971^{* *}$ & $0.962^{* *}$ & $0.340^{* *}$ \\
\hline & FM & & & & & & & & 1 & $0.967^{* *}$ & $0.320^{* *}$ \\
\hline & FMI & & & & & & & & & 1 & $0.524^{* *}$ \\
\hline & BAI & & & & & & & & & & 1 \\
\hline
\end{tabular}

* Correlation is significant at the 0.05 level (2 tailed).

${ }^{* *}$ Correlation is significant at the 0.01 level ( 2 tailed).

TABLE 5: (a) Impact of age on overall and central adiposity measures among adult male Mundas $(n=106)$. (b) Impact of age on overall and central adiposity measures among adult male Oraons $(n=104)$.

(a)

\begin{tabular}{lcccccc}
\hline Dependent variables & $B$ & SEB & Beta & $t$ & Sig & Adjusted $R^{2}$ \\
\hline WC & 71.392 & 1.602 & 0.062 & 44.567 & 0.000 & -0.006 \\
BMI & 21.739 & 0.765 & -0.202 & 28.432 & 0.000 & 0.032 \\
WHR & 0.872 & 0.014 & 0.265 & 63.652 & 0.000 & 0.061 \\
WHTR & 0.440 & 0.010 & 0.137 & 44.363 & 0.000 & 0.009 \\
CI & 1.132 & 0.020 & 0.265 & 55.780 & 0.000 & 0.061 \\
PBF & 7.530 & 1.018 & -0.046 & 7.394 & 0.000 & -0.007 \\
FM & 4.099 & 0.630 & -0.065 & 6.511 & 0.000 & -0.005 \\
FMI & 1.560 & 0.238 & -0.051 & 6.554 & 0.000 & -0.007 \\
BAI & 21.673 & 0.772 & -0.024 & 28.071 & 0.000 & -0.009 \\
\hline
\end{tabular}

Where; $B$ refers to regression coefficient. SEB refers to standard error of $B$. Beta refers to estimated regression coefficient. Sig. means level of significance.

(b)

\begin{tabular}{lcccccc}
\hline Dependent variables & $B$ & SEB & Beta & $t$ & Sig & Adjusted $R^{2}$ \\
\hline WC & 71.524 & 1.674 & -0.041 & 42.725 & 0.000 & -0.008 \\
BMI & 19.945 & 0.593 & -0.348 & 33.612 & 0.000 & 0.112 \\
WHR & 0.868 & 0.013 & 0.225 & 66.579 & 0.000 & 0.041 \\
WHTR & 0.444 & 0.011 & 0.007 & 38.626 & 0.000 & -0.010 \\
CI & 1.126 & 0.021 & 0.256 & 54.755 & 0.000 & 0.000 \\
PBF & 8.343 & 0.925 & -0.100 & 9.023 & 0.000 & 0.000 \\
FM & 4.631 & 0.589 & -0.143 & 7.866 & 0.000 & 0.011 \\
FMI & 1.791 & 0.225 & -0.136 & 7.946 & 0.000 & 0.009 \\
BAI & 22.418 & 1.034 & -0.115 & 21.687 & 0.000 & 0.003 \\
\hline
\end{tabular}

Where; $B$ refers to regression coefficient. SEB refers to standard error of $B$. Beta refers to estimated regression coefficient. Sig. means level of significance. 
All other used formulae are as follows.

WHR: waist circumference $(\mathrm{cm}) /$ hip circumference (cm) [20].

WHTR: waist circumference $(\mathrm{cm}) /$ height circumference $(\mathrm{cm})[21]$.

$\mathrm{CI}=$ waist circumference $(\mathrm{m}) / 0.109 \times \sqrt{ }$ weight $(\mathrm{kg}) / \sqrt{ }$ height $(\mathrm{m})[22]$.

Fat mass $(\mathrm{FM}, \mathrm{kg})=$ body weight $(\mathrm{Kg}) \times[\mathrm{PBF} / 100]$ [23].

Fat mass index $\left(\mathrm{FMI}, \mathrm{Kg} / \mathrm{m}^{2}\right)=\left[\mathrm{FM}(\mathrm{Kg}) /\right.$ height $^{2}$ $\left.\left(\mathrm{m}^{2}\right)\right][23]$.

Body adiposity index $(\mathrm{BAI})=[$ hip circumference $(\mathrm{cm}) /($ height $\times \sqrt{ }$ height $)]-18[24]$.

An independent Student's $t$-test was employed to compare the significance of the difference between anthropometric and their derived measured in cross validation. Ethnic difference in prevalence of CED based on BMI was also accessed by chi-square $\left(\chi^{2}\right)$ test. Pearson correlations and linear regression equations were computed to check the association of age with used adiposity measures. All computations were carried out using the Statistical Package for Social Sciences (SPSS-16) version. Statistical significance was set at $P<0.05$.

\section{Results}

The mean age in years of Mundas $(36.2 \pm 13.3)$ and Oraons $(35.1 \pm 15.3)$ were similar. Table 1 shows the mean \pm standard deviation and Student's $t$-test of anthropometric variables of the adult males belonging to two different communities. Both groups were almost similar except for chest circumference (79.32 $\pm 3.86 ; t=1.428 ; P<0.05)$ and anterior thigh skinfold $(6.40 \pm 2.09 ; t=0.461 ; P<0.05)$ that showed significant difference.

Table 2 shows the overall adiposity and central adiposity measures derived from anthropometric measurements. There existed no significant ethnic differences in all the derived overall and central adiposity measures. Thus we may conclude that these two communities do not vary with respect to overall and central adiposity.

In Table 3, nutritional status and health status of the studied two male communities measured and assessed by the WHO [16] recommended cut-off values of BMI, and Nieman [18] recommended cut-off point values for PBF are presented. The rates of undernutrition (CED; BMI $\leq 18.49 \mathrm{~kg} / \mathrm{m}^{2}$ ) in both male groups were observed to be very high (critical situation), and Mundas were found to have higher prevalence (50.0\%) of CED compared to the Oraons (46.2\%). Chi-square test results revealed that there was no significant ethnic difference between the two communities with respect to the nutritional status based on BMI $\left(\chi^{2}=0.467, \mathrm{df}=2\right.$, sig $=0.792)$. It also presents the distribution of percent body fat $(\mathrm{PBF})$ levels among the subjects. The results show that a considerable proportion of Mundas (29.3\%) and Oraons (35.4\%) have unhealthy (too low) PBF (i.e., $\leq 5 \%$ ) levels of body fat. There was no significant community difference $\left(\chi^{2}=1.196, \mathrm{df}=2, \operatorname{sig}=0.550\right)$ in body fat using PBF.

Table 4 shows the correlation matrix of age, $\mathrm{Wt}, \mathrm{BMI}$, WHR, WHTR, CI, PBF, FM, FMI, and BAI for both communities. The results revealed significantly negative correlations $(r=-0.202, P<0.05)$ between age and BMI among Mundas and positive correlation $(r=0.265, P<0.01)$ between age, WHR, and CI. Similarly among Oraons significantly negative correlation $(r=-0.348, P<0.01)$ between age and BMI was observed. Positive correlation was observed between age with WHR $(r=0.225, P<0.01)$ and CI $(r=0.256, P<0.01)$.

Tables 5(a) and 5(b) show the linear regression analysis, carried out (with age as an independent variable) to record the impact of age on overall adiposity and central adiposity measures as the dependent variables (WC, BMI, WHR, WHTR, CI, PBF, FM, FMI, and BAI) in both communities. The results indicate that age has a significant impact on all overall adiposity and central adiposity measures of both the communities. The result of Tables 4 and 5 also demonstrates that the mean values of almost all the overall and central adiposity measures decrease with increasing age.

\section{Discussion}

Nutritional status based on BMI with age, sex, and ethnicity have been widely studied. The contribution we have made in this paper is to evaluate the health and nutritional status patterns, using a well-tested methods among two different adult tribal male groups using BMI and PBF. When using a weight-height index to assess body fat, it is necessary not only that this index has a high correlation with PBF, but also that this index is not correlated with body height [25] unless one assumes that body height and PBF are correlated [26]. The present study found that for all anthropometrical variables in Munda and Oraon male tribals, the mean values are not significantly different from each other except for CC, and ATSF.

In both clinical practice and epidemiology, BMI is the most used indicator to determine both the individual and collective general nutritional status. This index is considered to positively correlate with certain health and longevity indicators $[27,28]$. In the present study, nutritional status as determined using the BMI $\left(<18.5 \mathrm{~kg} / \mathrm{m}^{2}\right)$ was higher in Mundas (50.0\%) than in Oraons (46.2\%). Similarly, the health status determined using PBF was slightly higher in Oraons (35.4\%) than in Mundas (29.3\%).

Low weight $(\mathrm{BMI}<18.5)$ in men and women has been reported to be associated with decreased physical, social, and mental wellbeing. Both overweight and low weight values were associated with a lower quality of life, worse physical performance, and less physical wellbeing [29].

\section{Conclusion}

Our findings suggest that we can use BMI and PBF in identifying individuals who are experiencing nutritional stress. It had been clear that using BMI the prevalence of undernutrition was very high (critical situation), both among 
Munda and Oraons males. On the other hand using PBF it showed that (29.3\%) Mundas and (35.4\%) Oraons had low body fat percentage. Prospective studies are required to determine the associations between health status and PBF as well as nutrition status and BMI in different indigenous ethnic groups of India and elsewhere. This is particularly important for a country like India which is a home to numerous indigenous populations. Of paramount necessity is the use of PBF to study nutritional and morbidity status. Hitherto, there is a paucity on information on these variables among tribal populations of India.

\section{Acknowledgments}

All participating subjects and villagers are greatly acknowledged for their cooperation. However, the authors assume full responsibility for all data and content presented. Bigitendriya Debsharma received financial assistance in the form of Rajiv Gandhi National Fellowship (UGC-RGNF) from the University Grants Commission, Government of India.

\section{References}

[1] International Institute for Population Sciences (IIPS) and Macro International, National Family Health Survey (NFHS III), 2005-2006, vol. 1, International Institute for Population Sciences (IIPS), Mumbai, India, 2007.

[2] T. Kelly, W. Yang, C. S. Chen, K. Reynolds, and J. He, "Global burden of obesity in 2005 and projections to 2030," International Journal of Obesity, vol. 32, no. 9, pp. 1431-1437, 2008.

[3] "Everything You Want to Know About Body Fat," http://www .shapeup.org/bfl/basics1.html.

[4] P. Deurenberg, J. A. Weststrate, and J. C. Seidell, "Body mass index as a measure of body fatness: age- and sex-specific prediction formulas," British Journal of Nutrition, vol. 65, no. 2, pp. 105-114, 1991.

[5] D. Gallagher, M. Visser, D. Sepúlveda, R. N. Pierson, T. Harris, and S. B. Heymsfieid, "How useful is body mass index for comparison of body fatness across age, sex, and ethnic groups?" The American Journal of Epidemiology, vol. 143, no. 3, pp. 228239, 1996.

[6] P. Deurenberg, M. Yap, and W. A. van Staveren, "Body mass index and percent body fat: a meta analysis among different ethnic groups," International Journal of Obesity, vol. 22, no. 12, pp. 1164-1171, 1998.

[7] P. Deurenberg, M. D. Yap, J. Wang, F. P. Lin, and G. Schmidt, "The impact of body build on the relationship between body mass index and percent body fat," International Journal of Obesity, vol. 23, no. 5, pp. 537-542, 1999.

[8] World Health Organization, International Association for the Study of Obesity, and International Obesity Task Force, The Asia-Pacific Perspective: Redefining Obesity and Its Treatment, Health Communications, Sydney, Australia, 2000.

[9] WHO Expert Consultation, "Appropriate body-mass index for Asian populations and its implications for policy and intervention strategies," The Lancet, vol. 363, no. 9403, pp. 157-163, 2004.

[10] A. Dasgupta, A. Butt, T. Saha, G. Basu, A. Chattopadhyay, and A. Mukherjee, "Assessment of malnutrition among adolescents: can BMI be replaced by MUAC?" Indian Journal of Community Medicine, vol. 35, no. 2, pp. 276-279, 2010.
[11] S. C. Roy, The Oraon of Chota Nagpur, Brahmo Mission Press, Calcutta, India, 1915.

[12] T. G. Lohman, A. F. Roche, and R. Martorell, Anthropometric Standardization Reference Manual, Human Kinetics Books, Chicago, Ill, USA, 1988.

[13] Census of India. West Bengal. Data Highlights: The Scheduled Tribes, 2001.

[14] S. J. Ulijaszek and D. A. Kerr, "Anthropometric measurement error and the assessment of nutritional status," British Journal of Nutrition, vol. 82, no. 3, pp. 165-177, 1999.

[15] http://tribesindia.com/index.php?option=com_content\&view= article\&id= 240\&Itemid=104\&lang=en.

[16] World Health Organization, "Physical status: the use and interpretation of anthropometry," Tech. Rep. 854, World Health Organization, Geneva, Switzerland, 1995.

[17] S. Siri, "Body composition from fluid spaces and density: analysis of methods," in Techniques for Measuring Body Composition, J. Brozek and A. Henschel, Eds., pp. 223-234, National Academy of Sciences, Washington, DC, USA, 1961.

[18] D. C. Nieman, Exercise Testing and Prescription: A HealthRelated Approach, Mayfield, Mountain View, Calif, USA, 4th edition, 1999.

[19] J. V. G. A. Durnin and J. Womersley, "Body fat assessed from total body density and its estimation from skinfold thickness: measurements on 481 men and women aged from 16 to 72 years," British Journal of Nutrition, vol. 32, no. 1, pp. 79-97, 1974.

[20] World Health Organization, "Waist Circumference and WaistHip Ratio," Report of A WHO Expert Consultation, Geneva, Switzerland, 2008.

[21] A. Koster, M. F. Leitzmann, A. Schatzkin et al., "Waist circumference and mortality," The American Journal of Epidemiology, vol. 167, no. 12, pp. 1465-1475, 2008.

[22] R. Valdez, J. C. Seidell, Y. I. Ahn, and K. M. Weiss, "A new index of abdominal adiposity as an indicator of risk for cardiovascular disease. A cross-population study," International Journal of Obesity, vol. 17, no. 2, pp. 77-82, 1993.

[23] T. B. Van Itallie, Y. Mei-Uih, S. B. Heymsfield, R. C. Funk, and R. A. Boileau, "Height-normalized indices of the body's fat-free mass and fat mass: potentially useful indicators of nutritional status," The American Journal of Clinical Nutrition, vol. 52, no. 6, pp. 953-959, 1990.

[24] R. N. Bergman, D. Stefanovski, T. A. Buchanan et al., "A better index of body adiposity," Obesity, vol. 19, no. 5, pp. 1083-1089, 2011.

[25] A. Keys, F. Fidanza, M. J. Karvonen, N. Kimura, and H. L. Taylor, "Indices of relative weight and obesity," Journal of Chronic Diseases, vol. 25, no. 6-7, pp. 329-343, 1972.

[26] J. S. Garrow and J. Webster, "Quetelet's index $\left(\mathrm{W} / \mathrm{H}^{2}\right)$ as a measure of fatness," International Journal of Obesity, vol. 9, no. 2, pp. 147-153, 1985.

[27] E. E. Calle, M. J. Thun, J. M. Petrelli, C. Rodriguez, and C. W. Heath, "Body-mass index and mortality in a prospective cohort of U.S. adults," The New England Journal of Medicine, vol. 341, no. 15, pp. 1097-1105, 1999.

[28] H. H. Keller and T. Østbye, "Body mass index (BMI), BMI change and mortality in community-dwelling seniors without dementia," Journal of Nutrition, Health and Aging, vol. 9, no. 5, pp. 316-320, 2005.

[29] L. L. Yan, M. L. Daviglus, K. Liu et al., "BMI and health-related quality of life in adults 65 years and older," Obesity Research, vol. 12, no. 1, pp. 69-76, 2004. 

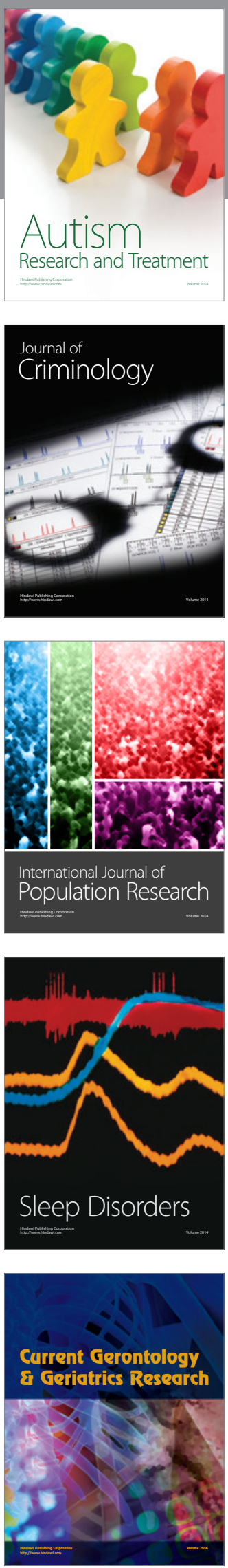
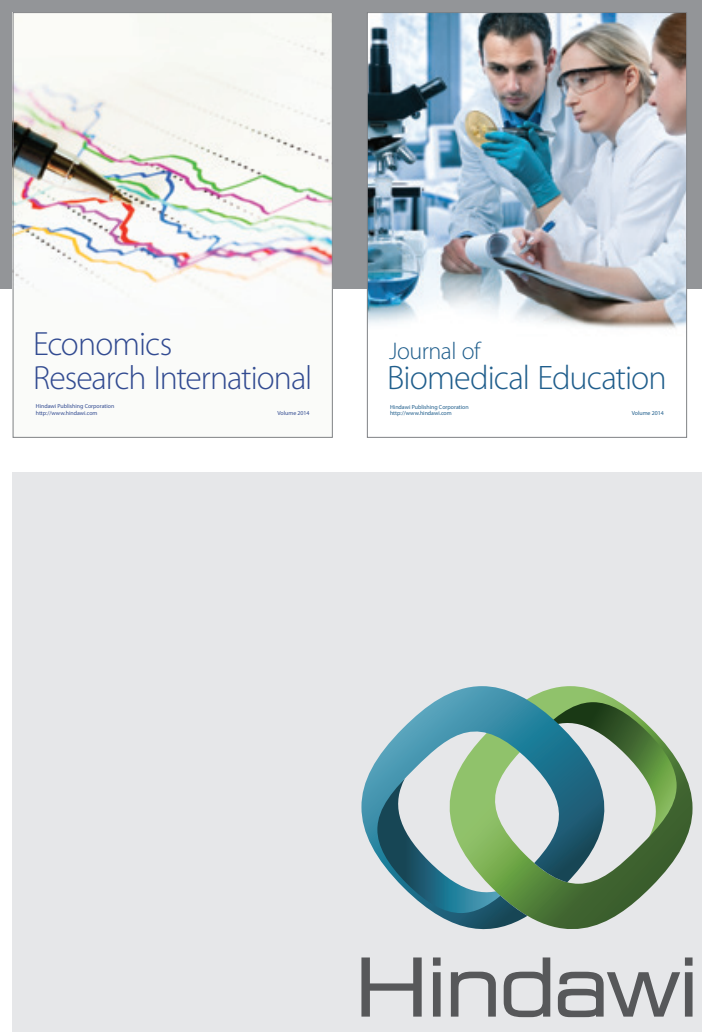

Submit your manuscripts at

http://www.hindawi.com
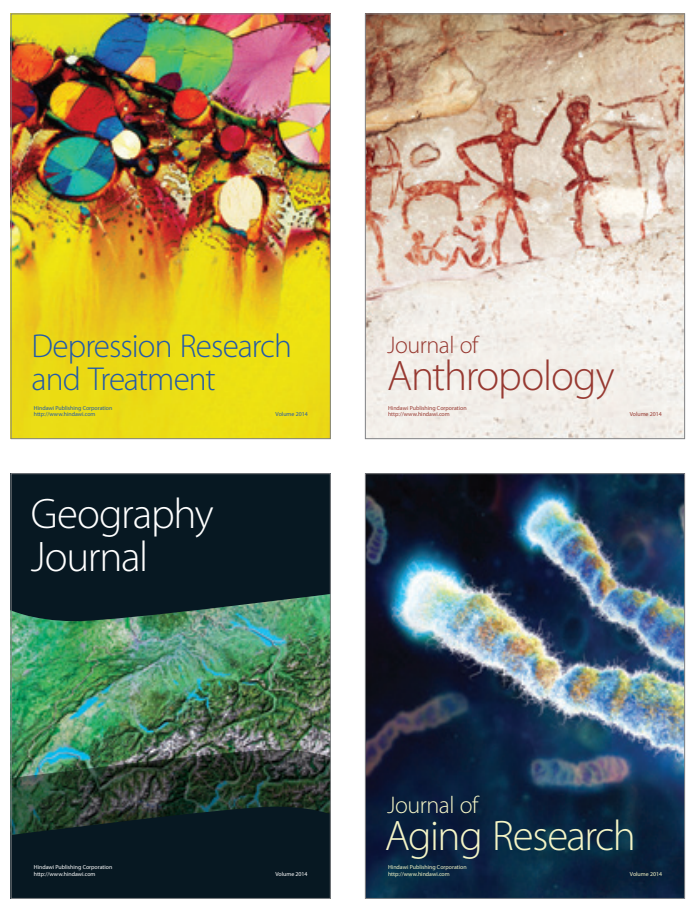
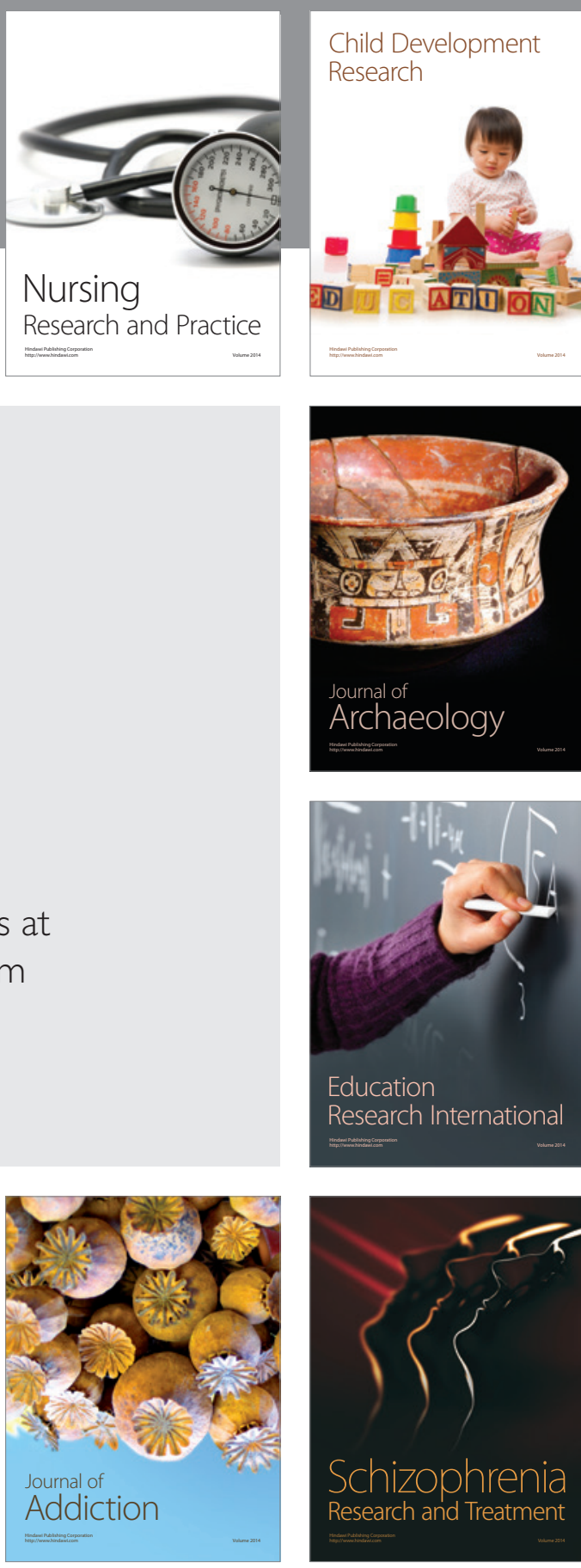

(D)
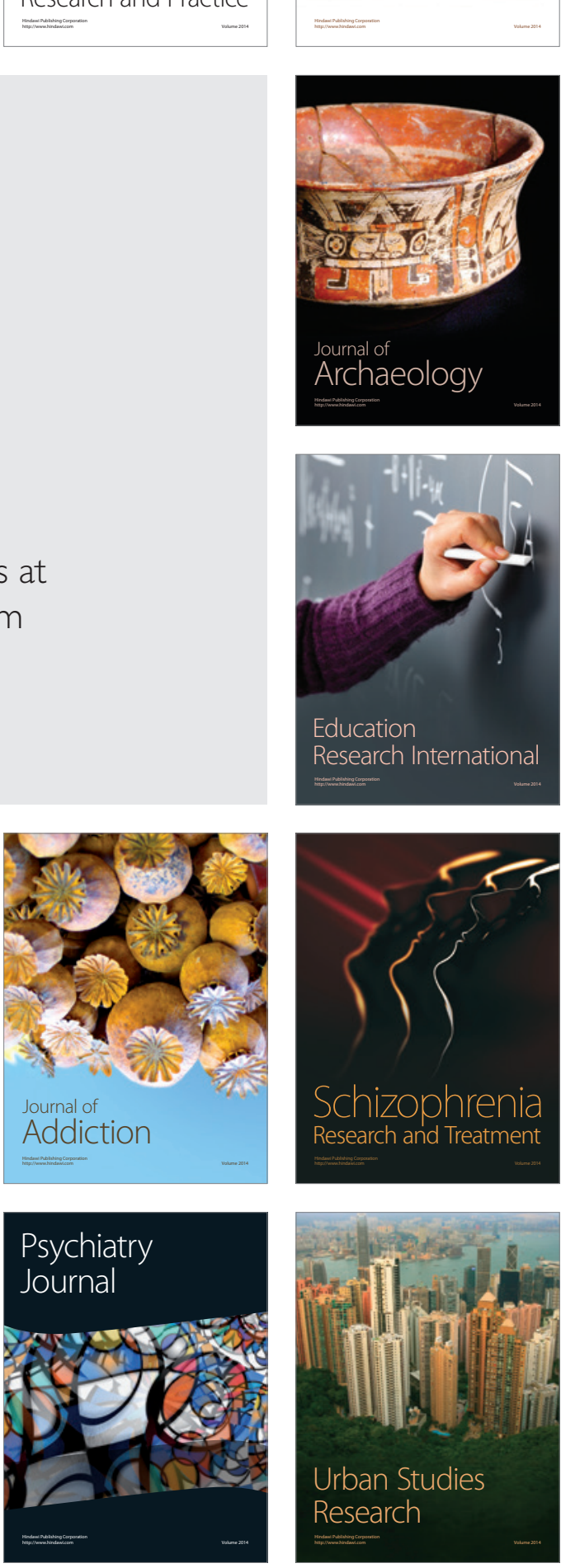